\title{
Repercussões do abuso sexual incestuoso sobre a relação mãe X filha
}

(Repercussions of incestuous sexual abuse on the mother/daugther)

(Efectos del abuso sexual incestuoso de la madre y la hija)

\author{
Maria Cristina Lopes de Almeida Amazonas* \\ Patrícia de Almeida Oliveira \\ Liliane Maria Martins de Barros Melo ${ }^{* *+}$
}

\begin{abstract}
Resumo
Esta pesquisa buscou compreender a relação entre mães e filhas após a descoberta e denúncia do abuso sexual incestuoso sofrido pela criança. Foram entrevistadas quatro mulheres que denunciaram o abuso incestuoso sofrido pelas filhas. Suas falas foram submetidas à análise de conteúdo. Os resultados demonstram que essas mulheres são muito exigentes em relação a si mesmas quanto ao papel de mães e conduzem as relações com suas filhas numa tentativa constante de protegê-las. Esse desejo de proteger a filha é tão forte, que dificulta a construção de novos relacionamentos amorosos. Todas apresentam medo de confiar novamente em um parceiro, tendo em vista o temor de que ele possa se tornar um novo agressor de sua filha. Isso permite pensar na dificuldade dessas mulheres de viver novos relacionamentos amorosos ou mesmo conviver com outros homens em espaços comuns.
\end{abstract}

Palavras-chave: violência sexual intrafamiliar; relacionamento afetivo; mulher; mãe.

\begin{abstract}
This research aimed to understand the relationship between mothers and daughters after the discovery and denouncement of incestuous abuse suffered by the child. Four women who have denounced the abuse suffered by their daughters were interviewed. Their speeches were submitted to Content Analysis. Results show that those women are very strict about their mother role, and conduct the relationship with their
\end{abstract}

\footnotetext{
Texto recebido em junho de 2008 e aprovado para publicação em setembro de 2009.

Doutora em Psicologia pela Universidade de Deusto (Espanha), professora do Mestrado em Psicologia Clínica da Universidade Católica de Pernambuco - Unicap. E-mail: crisamaz@elogica.com.br.

** Graduanda do curso de Psicologia da Universidade Católica de Pernambuco - Unicap. Bolsista da iniciação científica. E-mail: patriciaoliveira85@gmail.com.

*** Mestra em Psicologia Clínica pela Universidade Católica de Pernambuco - Unicap. E-mail: lilianebmelo@yahoo.com.br.
} 
daughters in a constant attempt to protect them. This wish to protect their daughters is so strong that it makes it harder to build new loving relationships. All of them show fear in trusting someone again, fearful that the partner can become a new aggressor of their daughters. This allows one to think about the difficulties those women have in living new loving relationships or even in dealing with other men who share common spaces with them.

Keywords: intra-familiar sexual violence; affective relationship; woman; mother.

\section{Resumen}

Esa investigación intentó comprender la relación madre-hija después de la descubierta y denuncia del abuso incestuoso sufrido por la niña. Fueron entrevistadas cuatro mujeres que han denunciado el abuso incestuoso sufrido por sus hijas. Sus hablas fueran sometidas al Análisis de Contenido. Los resultados demuestran que esas mujeres son muy exigentes consigo mismas en cuanto al rol de madres y conducen las relaciones con sus hijas intentando constantemente protegerlas. Este deseo de proteger a su hija es tan intenso que dificulta que ellas se construyan nuevas relaciones amorosas. Todas presentan miedo de confiar de nuevo en uno compañero, tiendo en vista el temor de que este se vuelva en uno nuevo agresor de su hija. Esto permite pensar en la dificultad de esas mujeres en vivenciar nuevas relaciones amorosas o mismo convivir con otros hombres en espacios comunes.

Palabras-clave: violencia sexual intrafamiliar; relaciones afectivas; mujer; madre.

\section{Introdução}

$\mathrm{N}$

a contemporaneidade, observa-se um crescente número de denúncias concernentes à prática da violência sexual no espaço familiar. Tendo em vista a interferência desse acontecimento na dinâmica relacional dessas famílias, percebe-se que, acompanhando esse cenário, há uma extensão do interesse e do empenho em ampliar o conhecimento científico quanto ao respectivo tema.

Para pesquisar o fenômeno do abuso sexual intrafamiliar, faz-se imperativa a compreensão de que isso acontece em uma instituição que, durante séculos, foi considerada sagrada e que faz parte do mundo privado. Na perspectiva de Lévi-Strauss (1984), essa instituição é compreendida como um dispositivo universal em que as ligaçôes sexuais entre determinados membros são interditadas e condenáveis. A família 
é, também, a instância incumbida de fornecer proteção e de prover afetivamente seus membros (Matias, 2006).

Além disso, ela é o primeiro espaço em que são transmitidas a cultura e as normas presentes na sociedade, sendo entendida como um contexto de reprodução ideológica, no qual ocorrem os primeiros aprendizados dos papéis sociais. Dessa forma, configura-se como a instância em que começa e se desenvolve o processo de construção tanto das identidades pessoais quanto da diferenciação entre seus membros. Tradicionalmente, é atribuída à família a função de estabelecer papéis, constituindo, assim, padrões de relacionamentos, de responsabilidades e de atividades (Dessen $\&$ Polonia, 2007). Na prescrição desses papéis, destaca-se a função da paternidade como marcada pela autoridade e pela sustentação de ordem primordialmente econômica, enquanto que, para a maternidade, caberia o cuidado e o acolhimento dos membros da família (Oliveira, 2007). É possível pensar nos papéis estabelecidos no espaço intrafamiliar com base em uma hierarquia semelhante às relações de poder existentes na sociedade. Nesse aspecto, caberia ao marido o máximo de autoridade sobre a mulher, desta se espera a submissão ao marido, e da mãe é cabível que exerça relativo poder sobre os filhos (Mendonça, 2002).

Mas, ao compreender a família inserida num macrocontexto e ao considerá-la como um sistema temporal, aberto, no qual as transformações se fazem presentes principalmente pela troca de informações com os sistemas extrafamiliares, deve-se ter em vista as diversas mudanças que ocorreram nessa instituição ao longo da história. Assim, as funções parentais e conjugais se apresentam em constante variação, sendo possível perceber as influências das novas formas de viver o público e o privado dentro dessa dinâmica familiar. Ainda que os modelos de família variem pelos tempos, todos apresentam a existência de um vínculo afetivo ligando os seus integrantes. Tendo em vista essa compreensão, ressalta-se o olhar quanto ao problema do incesto do ponto de vista dos vínculos que se estabelecem entre os membros da família (Matias, 2006).

Segundo Lévi-Strauss (1976), a interdição do incesto tem a função de fazer surgirem leis que atuem regendo as unióes matrimoniais, estabelecendo as configurações de interação entre as famílias. De acordo com o mesmo autor, a proibição do incesto se deve ao fato de que o ser humano é, concomitantemente, um ser biológico e um ser social. Essa dupla natureza remete à ambiguidade inata do indivíduo, tendo em vista que, como ser biológico, desejaria a ocorrência do incesto e, como ser cultural, a evitaria. Nesse aspecto, a abdicação dos desejos incestuosos possibilitaria ao ser humano ultrapassar o caráter estabelecido pela natureza, permitindo atingir a ordem da cultura. Com base 
nesse pressuposto, pode-se pensar que o inverso, a satisfação desses desejos, caracterizaria uma prevalência do ser biológico sobre o ser social, fazendo gerar conflitos nas interações entre os membros da família.

Ao contrastar a concepção já marcada de família (a família ideal, a sagrada, que, mesmo diante das mudanças, traz como função acolher e proteger) e a família em que existe a presença da violência sexual incestuosa, observa-se uma tendência a considerar esta última com características de insensibilidade, patologia e desestruturação. Os vínculos afetivos são pensados, nessas famílias, como sendo frágeis, tendendo à inexistência; a figura paterna e a figura materna são percebidas, de maneira geral, de forma inversa à percepção idealizada atribuída aos papéis parentais (Matias, 2006).

Amazarray e Koller (1998) demonstram que o incesto, assim como o abuso sexual infantil, é um fenômeno complexo e multideterminado. Entre os fatores que favorecem sua ocorrência, estão tanto os de ordem familiar quanto os de âmbito social. No primeiro caso, encontram-se pais que apresentam histórias de maus-tratos em sua infância, ignorância em relação aos cuidados dos filhos, um ciclo evolutivo de conflitos e agressões entre pais e filhos, relações conjugais empobrecidas, confusões de papéis na família, entre outros. Quanto aos fatores que se relacionam com questôes sociais, encontram-se o desemprego do pai de família ou baixo nível de satisfação no trabalho e atitudes da sociedade de tolerância à violência e à punição infantil.

No que tange mais especificamente ao abuso sexual incestuoso, essas mesmas autoras caracterizam a dinâmica dessas famílias como presença de pai alcoolista ou excessivamente autoritário e, ou, moralista; mãe extremamente passiva ou ausente; cônjuges com relação sexual inadequada; pais que acariciam seus filhos ou exigem deles determinado tipo de carícias inadequadas, violando a privacidade sexual; pais que ficam a sós com seus filhos por tempo demasiado; filhas desempenhando papéis de mães; filhas promíscuas ou que apresentam comportamento autodestrutivo; crianças isoladas e retraídas, com poucos amigos, que apresentam comportamento sexual inadequado para sua etapa de desenvolvimento. Acrescentam que essas famílias "costumam assumir atitudes de hostilidade diante de pessoas desconhecidas, e os pais dificilmente autorizam a entrevista de um profissional a sós com sua filha” (Amazarray \& Koller, 1998, p. 7).

Neste artigo, não nos deteremos nas causas que levam à ocorrência do incesto, nem mesmo enfocaremos a dinâmica dessas famílias, como um 
todo. Analisaremos as repercussões sobre o relacionamento afetivo entre mãe e filha após a descoberta pela mãe de que seu companheiro, pai de sua filha, cometeu abuso sexual incestuoso contra a criança.

Pesquisas embasadas em denúncias apontam que, quando se trata de tais práticas relacionais no ambiente doméstico e familiar, há uma maior predominância do homem, em destaque, do pai biológico, como agressor, e da filha, como vítima (Fonseca \& Capita, 2005; Drezett, Caballero \& Juliano, 2001; Saffioti, 1997). Outro dado significativo constatado nessas pesquisas diz respeito à predominância das denúncias feitas pela mãe da vítima. Cohen e Gobbetti (1998), ao observarem as denúncias realizadas no Centro de Estudos e Atendimento Relativos ao Abuso Sexual, constataram que a porcentagem maior de denúncias foi efetuada pela mãe, correspondendo a $48,31 \%$ dos casos.

No abuso sexual incestuoso, observa-se como protagonistas alguém que pratica o abuso e alguém que o sofre. Todavia os integrantes envolvidos não devem ser reduzidos meramente aos indivíduos diretamente implicados. Nesse sentido, o incesto é concebido como um problema fundamentalmente familiar, em que todos os membros, de alguma maneira, testemunham consciente ou inconscientemente o que ocorre na família. Testemunham algo que necessita ser conservado em segredo. A necessidade de manter o abuso incestuoso em segredo tem a função de manter a estrutura familiar.

Refletindo sobre o papel dessa mãe que denuncia, é possível pensá-la como rompendo com a barreira do que não pode ser dito, intuindo cumprir a função que lhe cabe. Pode-se cogitar que os papéis exercidos na família por essa mulher, diante da situação, entram em conflito. A mulher, mãe da vítima e companheira do agressor, vive uma ambivalência de sentimentos, visto que se apresentam duas situaçôes opostas: a de omitir o abuso e a de denunciá-lo. Como mãe, percebe-se obrigada a cuidar e a proteger o filho; como esposa, teme que, ao desfazer o segredo, desmorone seu ideal de família. A partir desse olhar, considerando a mulher que denuncia, pode-se cogitar que há um prejuízo quanto às relações afetivas dessas mulheres em relação às suas filhas, vítimas do abuso sexual incestuoso, visto que são múltiplos e conflituosos os sentimentos que vão atravessar essa relação.

Contextualizando essa mulher, observa-se que culturalmente a identidade feminina é percebida associada ao casamento, ao papel de esposa e ao papel de mãe, sendo a emocionalidade, a passividade e a domesticidade algumas das características consideradas universalmente como femininas (Pelloso \& Oliveira, 2004). Nesse aspecto, Nascimento (2006) enfatiza a função do 
contexto familiar quanto ao aprendizado da diferenciação dos papéis sexuais. A autora concebe que, dentro desse espaço, há uma distinção na maneira de educar os meninos e as meninas, preconizando, dessa forma, as pretensas hierarquias da diferença de sexo. Nessa perspectiva, faz-se notar que as mulheres apresentam uma educação direcionada à satisfação das necessidades dos homens da família. A mulher é concebida como dedicada e abnegada e com a função de cuidar, sendo o homem e os filhos os principais objetos desses cuidados. Essas normas de gênero entendem o feminino a partir do seu desempenho nos papéis de esposa e de mãe, remetendo a uma obrigatoriedade permanente de satisfazer as demandas cabíveis a essas funções.

Em geral, as mulheres internalizam os estereótipos presentes na cultura patriarcal sexista, compreendendo atitudes relativas ao seu papel na família e no casamento como sendo tipicamente femininas. Em oposição ao papel feminino, a concepção engendrada pelos papéis sexuais traz a compreensão de homem como sendo um ser fortemente sexual, no qual inexiste a capacidade de controle de seus impulsos. Essa perspectiva remete, mesmo que implicitamente, à compreensão de que o homem deve ser servido; assim, mostra-se imperativo atender a todas as suas necessidades, mesmo as sexuais, às quais a mulher, os filhos e filhas são obrigados a se submeter. A partir dessa perspectiva, pode-se pensar nas questôes sociais de poder e de gênero como estando fortemente relacionadas com a violência intrafamiliar (Narvaz \& Koller, 2006).

Tendo em vista as menções quanto às questôes de gênero, faz-se indispensável compreender a mulher na atualidade, considerando a aquisição de novas características e de novos posicionamentos. No entanto, mesmo diante dessas mudanças, ainda persiste com grande força o mito idealizado da boa mãe que protege e que cuida do filho (Mendonça, 2002). Em relação a isso, Serrurier afirma:

Aquilo que continua presente no inconsciente coletivo é a mãe ideal: dizer que ela é devotada seria pouco: ela é toda dada, toda maternal, ela se esquece completamente dela mesma para só pensar nos filhos. É a abnegação, a generosidade encarnada. Está sempre presente quando preciso. Podemos dizer-lhe tudo e pedirlhe tudo. É o consolo, a doçura, a ternura, a alegria. Ela é o todo (Serrurier, 1993, p. 64).

A autora percebe a mãe contemporânea estando atada a uma busca por cumprir um ideal construído, que exige da maternidade a abdicação de si em função dos cuidados com os filhos. Ela reflete sobre o sofrimento de mulheres/mães, tendo em vista as fortes exigências e responsabilidades a elas 
direcionadas e a vivência de possíveis conflitos diante da impossibilidade de atingir os atributos prescritos à boa mãe.

Badinter (1985), no mesmo sentido, concebe a maternidade como um mito, uma construção introduzida por valores sociais que têm a força de determinar os desejos das mulheres. Assim, Badinter concorda com Serrurier ao considerar que tais exigências provocam, em muitas mulheres, uma angústia para seguir um ideal e um sofrimento quando não é possível alcançá-lo.

Em vista dessas exigências quanto ao papel materno e considerando como atributos necessários nessa categoria o de cuidar e o de oferecer a devida segurança, a mãe cuja filha foi vítima de incesto se culpa por não a ter protegido do abuso (Mendonça, 2002).

Aliado a esse sentimento da mãe, observa-se, num relativo número de casos, que a vítima do abuso sexual incestuoso revela uma prevalência de sentimentos de raiva e de desprezo mais acentuados em relação à mãe do que ao próprio agressor (Cohen \& Gobbetti, 1998). É possível que esses sentimentos sejam decorrentes de fatores, tais como a demora, por parte da mãe, em denunciar a descoberta do abuso, a dificuldade de acreditar na veracidade do ocorrido ou mesmo a omissão inicial em virtude do temor das consequências da denúncia. Esses aspectos permitem refletir sobre um possível prejuízo nas relações afetivas entre essas mães e suas respectivas filhas. Segundo Araújo (2002, p. 7), a criança "tem raiva da mãe por não protegê-la e tem medo de contar, com receio de que não acreditem nela ou a considerem culpada".

\section{Metodologia}

Este trabalho é um recorte de uma investigação mais ampla que tratou da conjugalidade e parentalidade em mulheres cujos filhos foram vítimas de abuso sexual incestuoso. Foram entrevistadas quatro mulheres/mães de crianças do sexo feminino, com idades entre 1 e 4 anos, que foram vítimas de abuso sexual incestuoso, praticado pelo pai biológico. $\mathrm{O}$ abuso ocorreu durante o casamento de duas das quatro mulheres, sendo que duas delas estavam separadas dos seus companheiros, e o abuso se deu durante visitas da criança ao pai. As mães se encontravam na faixa etária entre 23 e 35 anos e tinham nível de escolaridade entre o ensino fundamental e o terceiro grau completo. Em relação ao poder aquisitivo, a faixa de ganho salarial variou de um a quatro salários mínimos. Todas foram entrevistadas individualmente e em ambiente privado. As entrevistas foram gravadas com o consentimento das participantes. A coleta se deu em um Centro de Defesa de Direitos Humanos, em local apropriado para atendimento psicológico. 
As entrevistas ocorreram em dois encontros. No primeiro, levantaram-se os dados de identificação da participante e, em seguida, foram mostradas às mulheres figuras representando diferentes configurações de família coladas em um caderno de desenho como uma espécie de álbum. Esse serviu de estímulo para dar início à entrevista, que partiu da seguinte solicitação: "eu gostaria que você me falasse do que vê nessa(s) foto(s)". As perguntas subsequentes decorreram da resposta inicial. Num segundo encontro, foram dirigidas perguntas, visando a esclarecer e aprofundar questões que emergiram durante o primeiro, quando as participantes se expressaram depois da apresentação do álbum.

As informações colhidas foram analisadas de acordo com o método de análise de conteúdo temática (Minayo, 1999). Inicialmente as entrevistas eram lidas uma a uma, tentando encontrar os principais núcleos de sentido ou temas. Essa leitura tinha como orientação os objetivos da pesquisa, mas estávamos atentas ao surgimento de temas diferentes daqueles enfocados pelos pesquisadores. Em seguida, as falas dos entrevistados foram reunidas em torno dos temas encontrados, e, a partir desse momento, foram realizadas as inferências e interpretaçōes, tomando por base a literatura consultada sobre o tema em questão. Assim, com base na leitura de todas as entrevistas, agrupamos o que era comum a elas e listamos três temas ou núcleos de sentido: 1) relacionamento conjugal da mulher/mãe da criança vítima de abuso sexual incestuoso, com o do pai da criança; 2) exercício da parentalidade nessa relação familiar, tanto por parte da mãe quanto do pai da criança; 3) repercussões do abuso sexual incestuoso sobre o relacionamento entre mãe e filha, após a descoberta e denúncia do incesto por parte da mãe.

Neste artigo, vamos analisar apenas o último tema: relacionamento mãefilha depois da descoberta e denúncia do incesto.

\section{Resultados e discussões}

As falas seguintes foram retiradas de forma fidedigna das entrevistas. Com o intuito de facilitar a leitura, ao final de cada trecho, encontra-se, entre parênteses, o nome da mãe. Advertimos que esses nomes são fictícios, tendo em vista cumprir o acordo de sigilo.

\subsection{Relacionamento mãe-filha depois da descoberta e denúncia do incesto}

Badinter (1985) afirma que há uma construção social da crença generalizada que considera como parte da natureza da mulher o instinto maternal. Ainda 
hoje, de acordo com Mello \& Dias (2004), é endereçado à mãe o papel de realizar os cuidados e a proteção dos filhos, abdicando, quando necessário, de si própria em prol da maternidade. Essas autoras apontam os sentimentos de culpa e as pressões experimentadas pelas mulheres como consequência da imposição desses atributos ao papel materno. Nessa perspectiva, é possível indagar o sofrimento e os possíveis danos causados na relação afetiva das mães cujas filhas sofreram o abuso incestuoso. É como se essas mães tivessem falhado em atender às expectativas sociais. Assim, seguem as falas que possibilitam tentar compreender como essas mães se relacionam com suas filhas após a situação de abuso.

[...] Quando nós sofremos abuso assim, dentro do nosso lar, a gente fica traumatizada e, muitas vezes, as mães perdem até... o jeito, perdemos a maneira, a gente já não sabe mais como... Eu pelo menos sou assim, eu não sei nem mais como brincar com minha filha, eu não tenho nem, assim, condições de brincar (Amanda).

A fala de Amanda denota, inicialmente, que o abuso sofrido é visto como uma violência contra toda a família e não apenas contra a criança. Ela diz: "Quando nós sofremos o abuso, dentro do nosso lar [...]" Além disso, a situação abusiva produz entraves que parecem provocar, nessa mulher, um bloqueio para se relacionar com a filha, gerando uma dificuldade de atuar como uma mãe carinhosa. O entendimento dos atributos e dos valores que acompanham o enunciado do ser mãe se traduz diante da abnegação de si, da presteza aos cuidados e a proteção dos filhos, e há uma tendência, enfatizada pelo determinismo biológico, em a vincular tanto a um instinto quanto a um destino natural da mulher (Meyer, 2003).

Em contrapartida, há a concepção que questiona esse essencialismo, essa universalização das características impostas à categoria mãe, e que considera a constituição dessa representação estando aliada aos mecanismos de poder e de saber (Meyer, 2003; Foucault, 1995). Essa concepção se guia por uma apreensão pluralizada e heterogênea do feminino, estendendo, assim, para a maternidade, e defendendo uma construção do ser mãe como um modo de subjetivação absolutamente contingente (Mouffe, 1993).

Seguindo esta última perspectiva, podemos dizer que Amanda, diante da situação de abuso incestuoso, defronta-se com a necessidade de reconstruir suas habilidades para desempenhar o papel de mãe, agora 
sob a influência da situação de incesto. Experimenta o conflito entre o que considera ser uma boa mãe e o sofrimento vivido que a impede de se sentir à vontade para brincar com a filha. Parece que tudo ficou contaminado.

A alocução subsequente de Amanda permite notar a ênfase quanto ao constrangimento que experimenta, sobretudo, diante de brincadeiras que exigem contato físico.

Perdi a noção de uma brincadeira com uma criança a partir do momento que aconteceu essa situação, que é quando ela vivia brincando com o pai, ela vivia assim em brincadeiras com o pai. E, quando ela fala em brincar, vem a lembrança do passado e não consigo assim, né? [...] Principalmente as brincadeiras de colo! [...] Muitas vezes ela me pede pra ficar no meu colo, uma vez ela sentou no meu colo e começou a fazer a mesma coisa que fazia com o pai e veio na minha mente o que tinha acontecido. [...] Isso pra mim ficou meio traumatizante, né? [...] Mas, mesmo assim, eu tenho que me recuperar disso [...] Porque isso impede tanto a criança desenvolver, não é? (Amanda).

A entrevistada associa as relações de contato físico com o tipo de relação que o agressor mantinha com a filha. Sendo assim, abdica de uma maior proximidade física, visto que esse tipo de atitude não permite que ela esqueça a situação a que sua filha foi submetida. Essa fala sugere a presença de uma luta interna entre o desejo de Amanda restabelecer uma relação de maior proximidade com sua filha, que considera fundamental para a criança, e a impossibilidade de satisfazer tal anseio, tendo em vista os sentimentos que emergiram diante da experiência da situação de abuso. Nota-se o sofrimento dessa mãe diante do conflito e a exigência que se faz para ultrapassar as suas barreiras internas, por mais difícil que seja, em beneficio da filha.

Da mesma forma, pode-se perceber a entrevistada Sofia cobrindo-se de exigências em busca de amparar melhor a filha, aliada a uma tolerância em entender as aflições da criança. Nesse aspecto, diz:

[...] Tem que buscar força dentro da gente e ter muita paciência com a criança que sofreu esse tipo de coisa que... É uma barra pra mãe, porque é em cima da mãe que ela vai vir [...] Mesmo o pai tendo feito uma agressão com ela [...] As crianças ficam com raiva da mãe pelo fato da gente proibir a visita. A mãe tem que ter muita paciência pra não 
tá batendo, não tá piorando ainda mais o nível de agressão na cabeça dela porque é muito difícil [...] Tem que ter muita paciência, muita força dentro de si (Sofia).

Com base na fala de Sofia, é possível notar a imperiosa interferência da situação do incesto na relação dela com a filha. Percebe-se que, assim como Amanda, o fato de ser mãe faz com que se sinta obrigada a resguardar e compreender a filha, ainda que isso custe muito a ela. É possível pensar que seu sofrimento é intensificado quando não se sente capaz de corresponder ao mito da boa mãe, aquela que oferece proteção, cuidado e abnegação, mesmo nas condições mais adversas, como é a da violência intrafamiliar. De acordo com Badinter (1985), ainda na contemporaneidade persiste a ideia da natureza instintiva e universal do amor materno, que concebe a mãe apresentando o sentimento mais puro e genuíno para com o seu filho. Essa autora entende a ideia de maternidade como um mito, uma construção, produzida pelas ideias de especialistas: médicos, filósofos, profissionais dos meios de comunicação de diferentes épocas. A esse respeito, Foucault (1995, p. 234) afirma que a profissão médica "exerce um poder sem controle sobre os corpos das pessoas, sua saúde, sua vida e morte". A obra de Freud (1976) pode ser vista como um exemplo desse poder. Nela há um entrelace entre feminilidade e maternidade, na qual a mãe é considerada como a personagem basal da família, responsável pela saúde e pela felicidade dos filhos. Da mesma forma, Winnicott (2002) apresenta a mãe com o papel fundamental e como responsável pela promoção de um ambiente facilitador ao desenvolvimento do filho, salientando a necessidade do papel de uma mãe suficientemente boa, presente e confiável. Essas considerações, que fazem repousar sobre a mãe fortes atributos e responsabilidades, foram repensadas por Serrurier (1993). Representante do pensamento contemporâneo da psicanálise, a autora reflete sobre o sofrimento de mulheres/mães que não conseguem atingir a representação consagrada de mãe abnegada e próxima da perfeição, trazendo à tona as fortes exigências e o conflito por não cumpri-las.

Assim, considerando o que apontam essas autoras e as falas de Amanda e Sofia, pode-se cogitar que, aliada às características que emergiram da situação de abuso e que se incorporaram à categoria em construção do ser mãe, há a necessidade de se considerar a cobrança, concomitante, de um ideal imposto por uma construção social que atormenta fortemente o imaginário feminino. Esses aspectos influenciam a relação dessas mães com suas filhas.

A fala de Sofia permite, além disso, observar outras dificuldades e dilemas vividos na relação mãe-filha, após a situação de abuso. Ela expõe que a filha culpa a mãe por não permitir a visita do pai, mesmo este sendo o seu 
agressor. Nesse aspecto, assemelha-se ao temor experimentado por Vilma com a possibilidade de que a filha venha a culpá-la como consequência do afastamento do pai. "Ela (a criança) lembra do que houve e o medo que tenho hoje é que ela diga: meu pai foi preso por sua causa. Eu não me arrependo de nada."

Essa culpabilização da genitora confirma o que Cohen \& Gobbetti (1998) observaram no Centro de Estudos e Atendimento Relativos ao Abuso Sexual, estudo já citado anteriormente, também confirmado por Araújo (2002), isto é, a tendência de a criança vítima de abuso sexual incestuoso desenvolver sentimentos negativos em relação à mãe, quer esta realize a denúncia, afastando-a do pai, quer ela se omita de fazê-lo, deixando-a desprotegida.

Outro aspecto relevante mencionado pelas duas entrevistadas é quanto à percepção das crianças em relação ao pai, visto que este, em muitos casos, não é percebido por elas como agressor. Assim, a criança deposita, em forma de agressividade, essa carga de culpa sobre a mãe, em virtude de que, no olhar da filha, é a genitora a responsável pelo distanciamento do pai, apresentando, dessa forma, um forte empecilho para o relacionamento entre a mãe e a filha.

No depoimento de Beatriz, é possível notar outro aspecto que permeia essa relação: o sofrimento da mãe diante do sofrimento da filha e das mudanças em seu comportamento como consequência do incesto.

Porque minha filha ficou agressiva. Tudo isso eu sofria, de ver ela com medo de sair na rua, de ir por um caminho que lembrava onde ele morava, ela ficava apavorada. Quer dizer, tudo isso era sofrimento pra mim, das consequências que ficou nela não é? (Beatriz).

A entrevistada traz em sua fala a ênfase numa preocupação quanto aos danos sofridos pela criança diante da situação de abuso e menciona, assim como Sofia, a agressividade presente na filha. A agressividade, porém, é trazida por Beatriz de maneira diferente. Essa mãe não aponta explicitamente a evidência de uma relação conflituosa, nem menciona um direcionamento do estado agressivo da filha à própria genitora.

Esse aspecto pode ser pensado ao contrapor a preocupação dessa mãe com sua filha, observada também nas outras três mulheres, com a tendência em se perceber as mães das vítimas de abuso intrafamiliar como sendo coniventes com a violência, passivas e ausentes enquanto mães (Amazarray \& Koller, 1998; Dias, 2005; Matias, 2006). As mulheres que participaram desta pesquisa apresentam outros atributos, demonstrando grande sofrimento diante da 
violência acontecida no espaço familiar, que provocou interferências diretas e indiretas no modo de se relacionarem com suas filhas.

O desejo intenso dessas mães de proteger suas filhas torna-se, inclusive, um impedimento para que elas reconstruam suas vidas e seus relacionamentos amorosos. O que se salienta é uma dificuldade enorme de voltar a confiar nos homens. As falas apresentadas a seguir permitem demonstrar esse aspecto.

[...] Quando a gente sofre, dentro do nosso lar pelo nosso esposo, a gente já não quer mais acreditar em homem nenhum! A gente já fica insegura, eu quando eu vejo qualquer um! [...] Eu sei que não vai acontecer porque nem todo homem é igual [...] Mas a partir do momento que você passa por uma situação, você passa a não confiar mais nas outras pessoas, não é? Eu já não posso confiar em homem (Amanda).

Da mesma forma, Sofia relata sua dificuldade em estabelecer um laço de confiança, ao mesmo tempo em que compreende que há pessoas confiáveis, porém, assim como Amanda, a situação de violência intrafamiliar produziu marcas que a impossibilitam de se desvincular de seu medo de repetir a situação de abuso. Ela ainda acrescenta o desejo de perder esse temor e demonstra a consciência de que as pessoas não são todas desmerecedoras de confiança.

Eu não tenho assim é... Confiança né? Eu tô pedindo a Deus condições pra que eu possa tirar isso tudo da minha mente, pra que eu possa confiar, porque tem pessoas que a gente pode confiar [...] Mas, no momento, eu ainda não confio em nenhum (Sofia).

O mesmo acontece com Vilma, que diz: "Eu fiquei com o pé atrás. É tanto que, agora, eu tô com uma pessoa há três meses. Ele ainda não foi na minha casa".

Beatriz, que já tentou um novo relacionamento, demonstra como a impossibilidade de voltar a confiar nos homens impede qualquer progresso nas relações amorosas.

[...] Mas aí, era toda uma proteção que eu colocava na minha porta (do seu quarto). Eu colocava de um jeito assim que qualquer passo que ele desse da cama, eu ouvisse e já ficava de pé. Eu vivia assim nesse terror. Então, tava me estressando [...] Mas aí, quando ele (ex-namorado) passou a ter mais intimidade com os meus filhos [...] apertou um medo, e aí, foi nesse momento, que eu não quis mais ele na minha vida (Beatriz). 
A observação presente nas quatro mulheres sobre a dificuldade em estabelecer uma relação de confiança pode ser corroborada pelos resultados encontrados por Matias (2006), com base em um estudo dos vínculos afetivos em famílias incestuosas. De acordo com essa pesquisa, o abuso incestuoso traz como consequências o rompimento de vínculos, as desconfianças, os temores e as inseguranças.

Assim, seguindo essa perspectiva e a fala das entrevistadas, torna-se possível pensar que, diante da presença acentuada da desconfiança, essas mulheres vivem novos relacionamentos amorosos permeados por grandes dificuldades. Essas dificuldades encontram-se vinculadas ao temor de que novamente possam atravessar uma situação de violência sexual na família. Ainda de acordo com Matias (2006), entende-se que essa desconfiança aparece perante o rompimento da premissa que habitava essas mulheres/mães, de que os parceiros, por serem pais das vítimas, estavam distantes da possibilidade de exercer tal violência. O depósito da confiança seria justificado ante a paternidade. Esse aspecto pode ser observado nas falas subsequentes: "Todo mundo falava: 'Como é que tu deixa a tua filha com teu marido sozinho, tu confia?’ Eu dizia: 'Eu confio porque é o pai’” (Amanda).

A entrevistada Sofia apresenta a estranheza da prática do marido enquanto pai da criança, dizendo:

[...] Se eu me casar novamente eu fico com medo do meu próprio marido, não é? Porque eu não sei, se o próprio pai teve condições de fazer isso, jamais eu sei o que seria de outro pai, de outro homem que não seja o pai dela (Sofia).

Vilma acompanha esse pensamento, falando: "O pai, fez o que fez, outra pessoa pode fazer". O distanciamento do pai como agressor pode ser compreendido diante da crença generalizada que concebe os membros da família como situados num espaço sagrado, cuja relação entre os que o habitam é de proteção (Meyer, 2003). Nessa perspectiva, os novos companheiros dessas mulheres sofrem uma dupla desconfiança. Primeiramente, por se apresentarem fora desse núcleo, não pertencem, assim, ao campo do sagrado. O segundo aspecto aparece diante da experiência dessas mulheres quanto ao rompimento brusco da confiança no pai e agressor de suas filhas, gerando, dessa forma, um desmoronamento de um ideal de paternidade, no qual não havia lugar para o abuso sexual e cuja função principal seria a da proteção dos filhos. Assim, parece não haver mais o lugar da confiança em suas relações.

Em contrapartida, as falas de Sofia e Beatriz, expostas a seguir, denotam um desejo e uma preocupação dessas mulheres de estabelecer novas relaçôes 
com a intenção de proporcionarem às suas filhas um outro e distinto referencial masculino. Nesse sentido, Beatriz afirma: “[...] Logo no início, na verdade, eu fui criando uma fantasia, não por mim, de que eu tava assim, precisando de uma pessoa, mas pelos meus filhos, deles terem contato, de meus filhos terem isso na vida deles não é?"

A entrevistada Sofia apresenta a mesma preocupação, dizendo:

[...] Assim minha preocupação maior é arrumar uma pessoa que sirva de exemplo para ela... [...] Uma pessoa que, num pior momento dela, desse aquela esperança a ela que existe gente que presta. Entendeu? Porque ela... ela fica preocupada também com isso, ela me pergunta: "se você arrumar outro marido e ele vir a fazer... coisa feia comigo?" Eu digo, eu não vou deixar, jamais eu vou deixar você sozinha com ninguém mais $[\ldots]$ (Sofia).

Sofia discorre ainda sobre o medo da filha quanto à possibilidade de ser submetida a um novo abuso sexual com outros parceiros que a mãe venha a ter. Nesse sentido, mostra-se presente uma cobrança explícita de que a mãe a proteja dessa situação. Pode-se ver, tanto na fala de Sofia quanto na de Beatriz, que a exigência da filha é confrontada com a vontade de que a criança perceba, em outros modelos masculinos, que é possível uma relação de confiança. Essas observações permitem cogitar que essas mulheres se encontram diante de posicionamentos conflituosos. De um lado, percebem a necessidade de oferecer à criança um novo e distinto exemplo de masculino; de outro, confrontam-se com o temor de expor suas filhas, da mesma maneira, a uma situação de violência sexual. Em ambos os posicionamentos, o sentimento que parece prevalecer nessas mulheres é o de que devem priorizar o bem-estar das filhas.

Desse modo, seus relacionamentos amorosos ficam sempre condicionados a uma preocupação com o bem-estar e a segurança das filhas. Essa consideração permite pensar numa perspectiva que entende e universaliza o ser mulher enlaçado ao ser mãe, gerando, assim, uma crença de que o papel materno se constitui como obrigatório e central às mulheres e se sobrepõe a qualquer outro (Mariano 2005).

Como decorrência desses impedimentos, três das entrevistadas demonstram a incerteza ou mesmo descrença na possibilidade de um recasamento. Assim, Sofia afirma:

Eu não sei se um dia eu vou me casar de novo porque tem essa criança, mas eu sei que, daqui pra lá, ela já tá maior, eu vou 
estar também mais tranquila, mais consciente e jamais vou deixar minha filha ficar só com estranho nenhum (Sofia).

Vilma, da mesma forma, apresenta-se desestimulada quanto à possibilidade de recasamento e preocupada em selecionar bem quem pode habitar seu espaço familiar: "Eu pensava mais em casar. Agora, eu penso mais na pessoa que eu vou colocar na minha casa".

Beatriz concorda com Sofia e Vilma, e evidencia, como o principal empecilho do recasamento, a situação de dividir a mesma moradia com outro homem.

Há um bloqueio, e eu não consigo. Na teoria, tudo bem, mas, na prática, na verdade, eu acordar todo dia, vai haver um bloqueio. Eu acho que vou viver eternamente só. Então, assim, poderia até casar, mas viver em casa separada, eu continuasse na minha casa, mas a gente morando junto, acordando todo mundo junto, não (Beatriz).

Tendo em vista essas falas, percebe-se que a possibilidade de recasamento aparece associada à repetição da situação de violência sexual intrafamiliar. Essa observação demonstra uma das repercussões provocadas pelo abuso incestuoso na vida afetiva dessas mulheres.

\section{Considerações finais}

Com base nesta pesquisa, é possível compreender algumas das repercussões do abuso sexual incestuoso sobre o relacionamento entre mãe e filha, assim como sobre a vida dessas mulheres, cujas filhas foram vítimas de incesto por parte de seus companheiros.

As falas dessas mães permitem perceber que, após a situação de abuso incestuoso, tornaram-se presentes nas relaçôes com suas filhas elementos como dificuldade de estabelecer relação de contato físico com a criança, agressividade da filha dirigida à própria genitora, sofrimento da mãe diante do sofrimento da filha e da mudança no comportamento desta, excesso de cuidado e de preocupação da mãe em relação à filha, e uma forte exigência que essas mulheres fazem a si mesmas quanto ao ser uma mãe capaz de proteger as filhas.

Essa condição aparece como impedimento para a construção de novos vínculos amorosos, visto que, para elas, a possibilidade de se relacionarem com outros parceiros encontra-se associada à repetição da situação de abuso sexual na família, o que prejudicaria sua busca por proteger a filha. A esse 
aspecto, adiciona-se, como característica compartilhada entre as entrevistadas, a marcante dificuldade em confiar em outros homens. Desse modo, percebese a situação de violência sexual intrafamiliar, interferindo e dificultando o relacionamento dessas mulheres com novos companheiros.

Dessa maneira, conclui-se que os danos sofridos pelo abuso sexual incestuoso estendem-se da filha, vítima direta da violência, às relaçôes afetivas dessas mulheres/mães que vivem essa situação e, consequentemente, a toda a família.

\section{Referências}

Amazarray, M. R. \& Koller, S. H. (1998). Crianças vítimas de abuso sexual: alguns aspectos observados em seu desenvolvimento. Psicologia, Reflexão e Critica, 11 (3), 559-578.

Araújo, M. F. (2002). Violência e abuso sexual na família. Psicologia em Estudo, 7 (2), 3-11.

Badinter, E. (1985). Um amor conquistado: o mito do amor materno. Rio de Janeiro: Nova Fronteira.

Cohen, C. \& Gobbetti, G. J. (1998). Abuso sexual intrafamiliar. Revista Brasileira de Ciências Criminais. 6 (24), 235-243.

Dessen, M. A. \& Polonia, A. C. (2007). A família e a escola como contextos de desenvolvimento humano. Ribeirão Preto: Paideia, 17 (36), 22-24.

Dias, M. B. (2005). Incesto: um pacto de silêncio. Boletim Brasileiro de Direito de Família, 5 (35), 2-5.

Drezett, J.; Caballero, M. \& Juliano, Y. (2001). Estudo de mecanismos e fatores relacionados com o abuso sexual em crianças e adolescentes do sexo feminino. Jornal de Pediatria, 77 (5), 417.

Fonseca, A. R. \& Capita, C. G. (2005). Abuso sexual na infância: um estudo de validade de instrumentos projetivos. PSIC: Revista de Psicologia, $6(1), 27-34$.

Foucault, M. (1995). O sujeito e o poder. In: H. Dreyfus \& P. Rabinow (Org.), Michel Foucault, uma trajetória filosófica: para além do estruturalismo e da hermenêutica. (pp. 231-249). Rio de Janeiro: Forense Universitária. 
Freud, S. (1976). Sexualidade feminina. In: S. Freud. Edição Standard das Obras Psicológicas Completas de Sigmund Freud (vol. 21, pp. 259-279). Rio de Janeiro: Imago (original publicado em 1931).

Lévi-Strauss, C. (1976). Antropologia estrutural. Rio de Janeiro: Tempo Brasileiro. v. 2.

Lévi-Strauss, C. A. (1984). Família. In: H. Shapiro (org.). Homem, cultura e sociedade. (pp. 308-333). São Paulo: Martins Fontes.

Mariano, S. (2005). O sujeito do feminismo e o pós-estruturalismo. Estudos feministas, 13 (3), 483-505.

Matias, D. P. (2006). Abuso sexual e sociometria: um estudo dos vínculos afetivos em famílias incestuosas. Psicologia em Estudo, 11 (2), 295-304.

Mello, I. S. P. B. \& Dias, C. M. S. B. (2004). Mãe que doa um filho: os vários ângulos da adoção. In: M. C. L. A. Amazonas; A. O. Lima (org.). Familia: diversos dizeres. (pp. 205-236). Recife: Bagaço.

Mendonça, M.C.V. (2002). Pedagogia da violência: as relaçôes de poder entre mãe e filha. Recife: Bagaço.

Meyer, D. E. (2003). Educação, saúde e modos de inscrever uma forma de maternidade nos corpos femininos. Movimento: Revista da Escola de Educação Física, 9, 33-58.

Minayo, M. C. (1999). O desafio do conhecimento: pesquisa qualitativa em saúde. São Paulo: Hucitec.

Mouffe, C. (1993). Feminismo, ciudadanía y política democrática radical. Debate Feminista, 4(7), 29-47.

Narvaz, M. G. \& Koller, S. H. (2006). A concepção de família de uma mulher-mãe de vítimas de incesto. Psicologia Reflexão e Crítica, 13 (3), 23-34.

Nascimento, C. R. R. (2006). Masculino e feminino no contexto da família: representaçôes sociais e práticas educativas em famílias de classe popular. Tese de Doutorado. Universidade Federal do Espírito Santo, Programa de PósGraduação em Psicologia, Vitória. 
Oliveira, M. C. F. A. (2007). O lugar dos homens na reprodução. In: M. A. Gutiérrez (org.). Género, familias y trabajo: rupturas y continuidades. (vol. 1, pp. 230-234). Buenos Aires: CLACSO.

Pelloso, S. M. \& Oliveira, A. F. (2004). Paradoxo e conflitos frente ao direito de ser mulher. Acta Scientiarum. 26 (2), 279-282.

Saffioti, H. I. B. (1997). No Fio da Navalha: Violência Contra Crianças e Adolescentes no Brasil Atual. In: F.R. Madeira (org.). Quem Mandou Nascer Mulher? (pp. 134-211). São Paulo: Rosa dos Tempos.

Serrurier, C. (1993). Elogio às mães más. São Paulo: Summus.

Winnicott, D. W. (2002). Os bebês e suas mães. São Paulo: Martins Fontes. (original publicado em 1964). 